\title{
Práticas de sustentabilidade a partir de uma visão Bourdiusiana
}

\author{
Sustainability practices from a Bourdiusian vision \\ Prácticas de sostenibilidad desde una visión Burdiusiana
}

Recebido: 13/11/2021 | Revisado: 19/11/2021 | Aceito: 19/11/2021 | Publicado: 29/11/2021

Antônio José dos Santos
ORCID: https://orcid.org/0000-0001-8657-3990
Eniversidade Regional do Noroeste do Estado do Rio Grande do Sul, Brasil
E-mail: antonio.santos@sou.unijui.edu.br
Sandra Beatriz Vicenci Fernandes
ORCID: https://orcid.org/0000-0001-5001-0774
E-mail: sandravf@unijui.edu.br
Danieli de Oliveira Biolchi
Universidade Regional do Noroeste do Estado do Rio Grande do Sul, Brasil
ORCID: https://orcid.org/0000-0002-3167-0352
E-mail: danieli.biolchi@unijui.edu.br
Airton Adelar Mueller
Universidade Regional do Noroeste do Estado do Rio Grande do Sul, Brasil
ORCID: https://orcid.org/0000-0001-6270-5856
E-mail: airton.mueller@unijui.edu.br
Maria Margarete Baccin Brizolla
Oniversidade Regional do Noroeste do Estado do Rio Grande do Sul, Brasil
ORCID: https://orcid.org/0000-0002-5120-0729
E-mail: marga.brizolla@unijui.edu.br

\section{Resumo}

O presente trabalho teve como tema as práticas de sustentabilidade a partir de uma visão Bourdiusiana. A metodologia adotada na formulação deste trabalho foi baseada em pesquisas bibliográficas, através de consultas a livros, revistas, pesquisa de manuais, tratados, artigos publicados na internet. A pesquisa bibliográfica procura explicar e discutir um tema com base em referências teóricas publicadas em livros, revistas, periódicos e outros. Assim, o objetivo geral busca analisar como ocorre a organização do desenvolvimento sustentável a partir da realidade dos ribeirinhos da região amazônica. Os objetivos específicos buscam descrever a visão Bourdiusiana sobre sustentabilidade, definir o que é desenvolvimento sustentável e sua presença na sociedade, apresentar a prática agrícola familiar de ribeirinho da Amazônia disponibilizada na literatura e por fim, compreender a partir de um estudo de caso a prática do desenvolvimento sustentável por ribeirinhos da região amazônica em suas práticas agrícolas. Os resultados indicam que a agricultura familiar sustentável vem contribuindo de maneira impar no desenvolvimento das economias locais, em especial em municípios com grandes demandas produtivas e que veem a agricultura familiar como fonte de renda para a movimentação de suas atividades econômicas. Por fim, o presente trabalho deixa o tema em aberto, propondo que no futuro se realize uma nova pesquisa afim de contextualizar os assuntos e estudo de campo aqui apresentado, dando continuidade no assunto abordado.

Palavras-chave: Ribeirinhos; Agricultura; Sustentabilidade.

\begin{abstract}
The present work had as its theme the sustainability practices from a Bourdius perspective. The methodology adopted in the formulation of this work was based on bibliographical research, through consultations in books, magazines, search of manuals, treatises, articles published on the internet. Bibliographic research seeks to explain and discuss a topic based on theoretical references published in books, magazines, periodicals and others. Thus, the general objective seeks to analyze how the organization of sustainable development takes place based on the reality of riverside dwellers in the Amazon region. The specific objectives seek to describe the Bourdiusian view on sustainability, define what sustainable development is and its presence in society, present the familiar agricultural practice of riverside people in the Amazon available in the literature and finally, understand, from a case study, the practice of sustainable development by riverside dwellers in the Amazon region in their agricultural practices. The results indicate that sustainable family farming has contributed in a unique way to the development of local economies, especially in municipalities with large productive demands and that see family farming as a source of income for the movement of their economic activities. Finally, the present work leaves the subject open, proposing that in the future a new research be carried out in order to contextualize the subjects and field study presented here, continuing the approached subject.
\end{abstract}

Keywords: Riverside; Agriculture; Sustainability. 


\begin{abstract}
Resumen
El presente trabajo tuvo como tema las prácticas de sustentabilidad desde la perspectiva de Bourdius. La metodología adoptada en la formulación de este trabajo se basó en la búsqueda bibliográfica, a través de consultas en libros, revistas, búsqueda de manuales, tratados, artículos publicados en Internet. La investigación bibliográfica busca explicar y discutir un tema a partir de referencias teóricas publicadas en libros, revistas, publicaciones periódicas y otros. Así, el objetivo general busca analizar cómo se da la organización del desarrollo sostenible a partir de la realidad de los ribereños de la región amazónica. Los objetivos específicos buscan describir la visión Bourdiusiana sobre la sostenibilidad, definir qué es el desarrollo sostenible y su presencia en la sociedad, presentar la práctica agrícola familiar de los pueblos ribereños de la Amazonía disponible en la literatura y finalmente, comprender, a partir de un estudio de caso, la práctica. del desarrollo sostenible de los habitantes ribereños de la región amazónica en sus prácticas agrícolas. Los resultados indican que la agricultura familiar sostenible ha contribuido de manera única al desarrollo de las economías locales, especialmente en municipios con grandes demandas productivas y que ven la agricultura familiar como una fuente de ingresos para el movimiento de sus actividades económicas. Finalmente, el presente trabajo deja abierto el tema, proponiendo que en el futuro se realice una nueva investigación con el fin de contextualizar los temas y estudio de campo aquí presentados, continuando el tema abordado.
\end{abstract}

Palabras clave: Orilla; Agricultura; Sustentabilidad.

\title{
1. Introdução
}

Os povos conhecidos no Brasil como "ribeirinhos" são aqueles que vivem próximo aos rios e utilizam a pesca artesanal como principal atividade de sobrevivência. Eles criam pequenos animais para consumo próprio e também podem se dedicar a atividades de mineração e autossuficiência (Parente, 2003).

Como os ribeirinhos vivem próximo aos rios é muito comum sua subsistência vir da pesca artesanal, caça, recuperação e indústrias extrativas. Devido aos fatores geográficos do país, grande parte dessa população está localizada na região amazônica. Além da população local, os descendentes de imigrantes do Nordeste do país também se somam a essa categoria (Silva, 2006).

O cultivo do milho e da mandioca, a produção de farinha e a coleta de nozes e açaí também desempenham um papel importante nas atividades agrícolas das comunidades ribeirinhas. A relação diferenciada com a natureza faz dos ribeirinhos amazônicos um importante detentor de conhecimentos sobre a fauna e a flora da floresta, o uso de plantas medicinais, o ritmo e o percurso das águas (Santos, 2014).

Visto o desenvolvimento de tais práticas para própria subsistência, é comum que elas sejam consideradas sustentáveis, uma vez que é necessário perpetuar os recursos então disponíveis para gerações futuras. Partindo deste cenário, este artigo buscará responder como ocorre a organização do desenvolvimento sustentável a partir da realidade dos ribeirinhos da região local amazônica?

Desta maneira, esta pesquisa terá como objetivo geral analisar como ocorre a organização do desenvolvimento sustentável a partir da realidade dos ribeirinhos da região amazônica. Assim, este artigo possui como objetivos específicos descrever a visão Bourdiusiana sobre sustentabilidade, definir o que é desenvolvimento sustentável e sua presença na sociedade, apresentar a prática agrícola familiar de ribeirinho da Amazônia disponibilizada na literatura e por fim, compreender a partir de um estudo de caso a prática do desenvolvimento sustentável por ribeirinhos da região amazônica em suas práticas agrícolas.

Justifica-se esta pesquisa sendo ela uma contribuição no âmbito acadêmico, a fim de acrescer ao conteúdo já existente sobre o tema, bem como, influenciar o contexto em que está inserido. Também justifica-se a pesquisa, sendo ela um material enriquecedor através de conteúdo conciso e compreensível ao leitor que possua conhecimento técnico ou não, proporcionado conhecimento mais aprofundado do tema.

\section{Metodologia}

O método adotado na formulação deste trabalho, encontra-se em concordância com a proposta de estudo, a qual encontra-se adequada por meio dos objetivos a serem alcançados. O desenvolvimento da ciência tem como base o alcance de resultados que permite validar hipóteses sobre determinado acontecimento ou fato, presente em nossas vidas, ou não. 
A pesquisa é de fundamental importância para a evolução dos conhecimentos em determinado campo de estudo, ou seja, por meio da pesquisa pode-se ampliar os horizontes de conhecimento sobre determinado tema.

Em um primeiro momento, a metodologia adotada na formulação deste trabalho foi baseada em pesquisas bibliográficas, através de consultas a livros, revistas, pesquisa de manuais, tratados, artigos publicados na internet. A pesquisa bibliográfica procura explicar e discutir um tema com base em referências teóricas publicadas em livros, revistas, periódicos e outros. Busca também, conhecer e analisar conteúdos científicos sobre determinado tema.

Para o presente estudo, utilizou-se os critérios de citações, pesquisas relacionadas ao tema, artigos que apresentam o tema em questão, artigos que não apresentam o tema, teses, dissertações além de textos, artigos e citações traduzidas.

Seguindo com o presente trabalho, realizou-se um estudo de caso, o qual fora desenvolvido sob uma abordagem qualitativa, que segundo Michael (2015) é definida, como aquela que se fundamenta na discussão de dados entre duas ou mais pessoas, analisando a partir do significado que estas dão aos seus atos. A autora afirma que tal pesquisa admite a verdade através de análise detalhada. Deve-se considerar que todos, mesmo aqueles menos dotados de conhecimento devem compreender e interpretar o exposto na discussão.

Seus fins, refere-se a uma pesquisa de caráter descritivo, que segundo Gil (2014), visa descrever as características de determinada população, fenômeno ou o estabelecimento de relações entre variáveis. Este tipo e pesquisa tem por finalidade, colocar o pesquisador em um contato direto com tudo o que fora escrito dito ou filmado sobre determinado assunto (Marconi \& Lakatos, 2011). A unidade de análise da pesquisa, se limitará à ribeirinhos da região Amazônica, buscando entender a visão deles sobre as práticas agrícolas e sua relação com a sustentabilidade. Segundo Collis \& Hussey (2005), a unidade de análise, pode ser compreendida como o objeto social, a partir do qual o estudo será embasado, ou seja, onde o fenômeno em questão estará sendo observado.

Para coleta de dados optou-se pela entrevista através de um questionário semiestruturado, que segundo Michael (2015), é uma conversação profissional entre duas ou mais pessoas, a fim da obtenção de informações a respeito de determinado assunto. A autora ressalta que a entrevista terá um resultado mais satisfatório se os entrevistados pertencerem ao grupo específico do assunto em questão, tendo em vista que esse terá melhor condição de fornecer informações relevantes para o resultado da pesquisa.

Sendo assim, a presente pesquisa poderá ser classificada como pesquisa de campo analítica, pois visará analisar os dados coletados por meio de um questionário aplicado in loco. Segundo Michael (2015) a pesquisa de campo consiste na verificação de como a teoria é aplicada na pratica e a pesquisa descritiva é definida por Vegara (2009) como aquela que relata as características de determinado fenômeno ou população, podendo relacionar com variáveis e definir sua natureza.

\section{Fundamentação Teórica}

\subsection{Teoria Bourdiusiana}

Pierre Bourdieu foi um renomado sociólogo e intelectual público que fez contribuições significativas para a teoria sociológica geral, teorizando a ligação entre educação e cultura e pesquisando as interseções de gosto, classe e educação. Ele é conhecido por ser o pioneiro de termos como "violência simbólica", " capital cultural " e "habitus" (Hurtado, 2010).

$\mathrm{O}$ trabalho de Bourdieu foi influenciado por fundadores da sociologia, incluindo Max Weber, Karl Marx e Émile Durkheim, bem como por outros estudiosos das disciplinas de antropologia e filosofia. Seu trabalho expõe os mecanismos por trás e dentro das tendências reprodutivas de educação, sociedade e cultura, que, por extensão, reproduzem práticas essencialmente insustentáveis (Loyal, 2007). 
Esta versão da teoria social de Bourdieu permite, então, nomear o que no capitalismo avançado sociedades tornam a sustentabilidade difícil de realizar, e como as tendências reprodutivas da educação pode ser usado para alcançar um "habitus de sustentabilidade" por meio de uma maior valorização do meio ambiente (Borim-de-Souza et al., 2018).

Ao explicar sua teoria social, Bourdieu costuma comparar a sociedade a um jogo, com diferentes jogadores possuidores de recursos (capitais sociais, econômicos e culturais) que recebem valores diferenciados dependendo do campo cultural em que atuam (acadêmico, político, econômico, etc.). Para Bourdieu, o campo é visto como um espaço estruturado de posições em que as posições e suas inter-relações são determinadas pela distribuição de diferentes tipos de recursos ou "capital" (Hurtado, 2010).

A trajetória dada por um agente através de qualquer campo particular será regidos por seus habitus individuais, constituído pelas sensibilidades e disposições incorporadas por interação familiar, educacional e social precoce. Embora a ação no passado possa ter sido orientada em relação à riqueza, prestígio, reconhecimento ou verdade, os cientistas ambientais postulam que, no futuro, o que está em jogo pode ser sustentabilidade ou destruição, resumindo, vida ou morte (Carvalho \& Steil, 2009).

Bourdieu por trás de sua teoria do habitus fornece um paralelo valioso para teorizar a conceituação "discreta" e insustentável de humanidade / natureza. Embora se concentre principalmente nas ações humanas, Bourdieu rejeita o existencialismo e o estruturalismo, negando assim a noção existencial do agente totalmente autônomo e a noção estruturalista de que é o ambiente, as estruturas que rodeiam as pessoas fazem parte delas (Borim-de-Souza et al., 2018).

As ações insustentáveis são, então, tanto uma forma de ignorância e história cultural incorporada quanto são o resultado do cálculo racional. Um processo essencial para alcançar a sustentabilidade será a alteração do habitus e Bourdieu nos permite teorizar maneiras pelas quais a educação pode contribuir para a produção de um "Habitus sustentável" através da introdução e acumulação de "capital ambiental” (Lessa, 2019).

Assim, a transição para uma sociedade ecologicamente sustentável envolve uma revolução sem precedentes nas instituições, sistemas, estilos de vida e valores. Grande parte da cultura ocidental precisa ser totalmente revertida. Temos que substituir uma longa lista de traços culturais por seus opostos, particularmente obsessões com a riqueza material, enriquecimento, competição, vitória, exercício de poder e controle da natureza (Loyal, 2007).

Esses traços e práticas culturais, observados como responsáveis pela cultura ocidental com práticas insustentáveis, correspondem ao conceito de prática de Bourdieu, sendo a somatização entre habitus capital ao campo, que resultam nas prática se ações (Hurtado, 2010).

Embora essa fórmula tenha sido projetada com campos culturais específicos em mente, pode se ajustá-la para levar em conta o impacto no supra campo ambiental, assim resultando em práticas e ações de alguma forma ecológicas. A simplicidade desta equação não pretende presumir que todas as práticas sejam sustentáveis ou insustentáveis, apenas que as práticas culturais não podem ser isoladas da natureza, em que todas as práticas impactam a ecologia (Borim-de-Souza et al., 2018).

O que esta equação sugere é que os espaços de intervenção para práticas ambientais sustentáveis são o habitus e o capital cultural. Enquanto os ambientalistas argumentam que as causas básicas dos problemas ambientais estão localizadas na própria natureza dos atuais sistemas sociais, econômicos e políticos e nas visões de mundo, instituições e opções de estilo de vida que os sustentam, a maioria das respostas científicas estão focadas apenas na natureza, o que serve para abdicar da cultura da responsabilidade de fazer mudanças no estilo de vida, como a valorização de um modo de vida sustentável (Lessa, 2019).

Uma compreensão sociológica da crise ambiental indica que o habitus como locus da cultura também precisa se tornar sustentável. A extensa teoria de Bourdieu contém muitas concepções complementares de habitus que contribuem com diferentes aspectos ou qualidades deste conceito corporificado, embora ele nunca tenha tentado um exposição teórica do habitus na sua totalidade. Assim, embora o conceito seja difícil de definir, ele também mantém uma certa fluidez que é útil para esta versão sustentável do habitus de Bourdieu (Carvalho \& SteiL, 2009). 
É neste contexto que um habitus sustentável está ciente da diferença entre uma "necessidade" e uma "necessidade cultivada", que está ciente das práticas insustentáveis usadas na produção de muitas "necessidades cultivadas" e assim converte capital econômico disponível com a sustentabilidade em mente (Lessa, 2019).

Um habitus sustentável refere-se a um habitus que interage de formas ecologicamente sustentáveis com a Terra, e não a um habitus imutável que é sustentado imutavelmente ao longo de seu ciclo de vida. Desta forma, a terminologia de "Sustentabilidade" está sendo usado de forma semelhante ao termo "desenvolvimento sustentável", no sentido em que usa o qualificador "sustentável" não apenas para inferir que o desenvolvimento pode potencialmente perpetuar-se ad infinitum, mas também que o desenvolvimento não afetará adversamente o ecossistema circundante do qual a vida depende (Borim-de-Souza et al., 2018).

"Sustentabilidade", neste caso, não está tanto preocupada com a perpetuação do desenvolvimento, mas com a perpetuação da vida fora do desenvolvimento. Da mesma forma, "habitus sustentável", em conjunto, refere-se a habitus, ou um estado coletivo de habitus, que pode perpetuar-se biológica e ecologicamente até a morte (Carvalho \& Steil, 2009).

Bourdieu pode dizer que o principal obstáculo para alcançar a sustentabilidade, mesmo que a maioria das pessoas no final sociedades capitalistas estariam cientes da crise ambiental e sumariamente cientes de suas causas, é que os esquemas do habitus, as formas primárias de classificação, devem sua eficácia específica ao fato de que funcionam abaixo do nível de consciência e linguagem, além do alcance do escrutínio ou controle introspectivo pela vontade (Lessa, 2019).

\subsection{Desenvolvimento Sustentável}

O desenvolvimento sustentável é uma abordagem do planejamento econômico que tenta promover o crescimento econômico, preservando a qualidade do meio ambiente para as gerações futuras. Por exemplo, uma floresta que fornecerá um rendimento sustentado de madeira em perpetuidade pode não suportar populações de aves nativas, e um depósito mineral que acabará por ser esgotado pode, no entanto, suportar mais ou menos sustentabilidade. A ideia de desenvolvimento sustentável domina as discussões do final do século XX sobre políticas de meio ambiente e desenvolvimento. É um termo chave em tratados, convênios e programas internacionais e está sendo escrito nas constituições dos estados-nação (Paula, Souza \& Souza-Pinto, 2012).

Mesmo aqueles que rejeitam o termo devem definir os pontos de vista em referência a ele. Apesar dessa influência, sérios problemas empíricos, conceituais e normativos devem ser abordados para que o termo sirva como uma estrutura abrangente de esforços para sustentar a biosfera e promover a realização humana, a segurança econômica e a justiça social em todo o mundo (Souza \& Fonseza, 2008).

"Sustentável" qualifica a ideia de desenvolvimento. Após a Segunda Guerra Mundial foi amplamente assumido que o desenvolvimento econômico levaria a maior liberdade, justiça e segurança para os povos do mundo. Quando as questões ambientais apareceram pela primeira vez na agenda internacional da Conferência de Estocolmo sobre o ambiente humano, em 1972, o debate foi se - e como - as preocupações com o meio ambiente e a equidade poderiam ser reconciliadas com o desenvolvimento econômico (Montibeller, 2007).

Nos anos seguintes, como as estratégias de desenvolvimento econômico falharam em fechar a lacuna entre ricos e pobres, dentro ou entre nações, e estudos mostraram crescimento da população e consumo mundiais aproximando-se dos limites biofísicos da Terra, foram levantadas questões sobre se a teoria do desenvolvimento poderia servir aos seres humanos ou necessidades ambientais e se não precisou ser modificado para incluir considerações ecológicas, políticas, sociais, culturais e espirituais (Leite, 2009).

A melhor abordagem para o gerenciamento ambiental é uma abordagem integrada, na qual todos os componentes do ambiente são levados em consideração e o gerenciamento adequado é feito como um todo. De acordo com abordagem 
conservadora, o homem não deve perturbar o sistema natural e deve se adaptar a ele. Mas isso não é possível porque, para todos os tipos de atividades de desenvolvimento, ele terá que usar a natureza e seus componentes, resultando em desequilíbrio ecológico de intensidade variada. A abordagem conservadora é que não deve haver exploração da natureza e a conservação dos recursos naturais é essencial para o desenvolvimento sustentável (Tadeu, 2012).

De fato, a utilização e conservação adequadas dos recursos é o principal objetivo da gestão ambiental. Na Estratégia Mundial de Conservação, os três principais objetivos declarados foram: a manutenção de processos ecológicos essenciais, a preservação da diversidade genética e a utilização sustentável dos recursos naturais. Nos últimos anos, diversas abordagens foram desenvolvidas para o gerenciamento do meio ambiente. Os planejadores regionais geralmente adotam uma abordagem de ecologia humana, enquanto outros sugerem uma análise de sistema ou uma abordagem de ecossistema (Paula, Souza \& SouzaPinto, 2012). As várias abordagens desenvolvidas para a gestão ambiental são:

- Abordagem ad hoc, desenvolvida em reação a uma situação específica;

- Abordagem de solução de problemas: para identificação de problemas e necessidades e implementação de soluções;

- Abordagem sistêmica: como ecossistema, agro ecossistema, etc. Abordagem regional: baseada em zonas ecológicas, como bacia hidrográfica, bacia hidrográfica, zona costeira, desenvolvimento da área de comando, ilha, etc.;

- Abordagem de disciplina especializada, frequentemente adotada por profissionais para gestão do ar, da água e da terra, gestão urbana, gestão do turismo e saúde ambiental;

- Abordagem voluntária do setor incentivada e apoiada por ONGs;

- Abordagem comercial: para gestão ambiental de negócios;

- Abordagem da ecologia humana, para estudo das relações entre seres humanos ou sociedade e natureza;

- Abordagem da ecologia política-, para desenvolver políticas e leis.

Além do acima, uma abordagem de sistema de gerenciamento ambiental (SGA) foi desenvolvida como uma abordagem integrada e proativa para questões ambientais. Ajuda a indústria ou outros órgãos e é projetado para garantir que uma política e objetivos ambientais sejam adotados e seguidos. No caso da abordagem ecossistêmica, o conceito de ecossistema tornou-se uma ferramenta conceitual amplamente usada para pesquisa após 1945. Atualmente, os ecologistas costumam adotar uma abordagem ecossistêmica ao procurar entender e monitorar uma determinada situação (Bartholomeu \& Caixeta-Filho, 2011).

O conceito de ecossistema permite que os gerentes ambientais considerem partes de natureza complexa como um sistema integrado. Pode ser aplicado a cidades ou agricultura (ecossistemas urbanos e agro ecossistemas, respectivamente). A abordagem do ecossistema permite uma visão holística de como os componentes funcionam juntos, ou seja, pode incorporar dimensões humanas no funcionamento da biosfera. Também ajuda a definir a escala temporal e espacial da gestão e, portanto, é uma abordagem multidisciplinar para lidar com as complexidades da função e uso do ecossistema (Leite, 2009)

A abordagem de ecologia política também estuda as relações entre sociedade e natureza. Ele afirma que mudanças radicais nos hábitos humanos são necessárias para combater a degradação ambiental e alcançar o desenvolvimento sustentável. É provável que sejam percepções diferentes das necessidades e problemas ambientais entre planejadores, formuladores de políticas, ministros, vários departamentos do governo, etc. Tudo isso pode ser efetivamente feito adotando uma abordagem ecológica política da gestão ambiental. Atualmente, tem havido uma ênfase crescente na gestão ambiental dos negócios, principalmente na abordagem comercial, bem como no papel das casas comerciais na proteção ambiental (Pereira et al., 2012). A ênfase está em:

- Gestão ambiental corporativa verde;

- Ética empresarial verde;

- Eco auditoria;

- Avaliação de impacto, avaliação de perigos e riscos; 
- Marketing verde, rotulagem;

- Reciclagem e disposição de resíduos;

- Investimento e financiamento ambientalmente saudáveis;

- Gestão da qualidade total.

A abordagem comercial envolve prioridade corporativa, educação dos funcionários, consultoria ao cliente, transferência de tecnologia, avaliação prévia, instalações e operações, pesquisa e conformidade e relatórios. Em suma, a abordagem ecológica, é o estudo das relações entre os seres humanos ou a sociedade e a natureza, através de uma abordagem multidisciplinar. Semelhante à abordagem do ecossistema, a ênfase principal nessa abordagem é a relação social com o meio ambiente, que é um aspecto primário de qualquer gerenciamento para planejamento e desenvolvimento (Paula, Souza \& Souza-Pinto, 2012).

A escala da abordagem pode ser local para global e apoia estudos holísticos. O conceito de "Avaliação de Impacto Social" procura avaliar se um desenvolvimento proposto altera a qualidade de vida e a sensação de bem-estar e como os indivíduos, grupos e comunidades adotam as mudanças causadas pelo desenvolvimento. Os aspectos socioeconômicos e biofísicos do meio ambiente estão interligados, portanto, para a gestão ambiental; a abordagem da ecologia humana deve ser adotada juntamente com a abordagem da ecologia política (Shibao, Moori \& Santos, 2010).

\subsection{Estudos Anteriores}

A agricultura familiar, inclui todas as atividades agrícolas de base familiar, e é um meio de organizar a produção agrícola, florestal, pesqueira, pastoril e aquícola que é administrada e operada por uma família e depende predominantemente do trabalho familiar, incluindo mulheres e homens. Além disso, os agricultores familiares desempenham uma função socioeconômica, ambiental e cultural de grande importância e, portanto, afetam o desenvolvimento sustentável, as pessoas e o planeta (Cabral, 2002).

A agricultura familiar produz mais de $80 \%$ dos alimentos do mundo. As fazendas familiares administram cerca de 70$80 \%$ das terras agrícolas em todo o mundo. Mais de $90 \%$ das fazendas são administradas por um indivíduo ou família. As mulheres fornecem quase 50\%\% da mão de obra agrícola, mas detêm apenas 15\% das terras agrícolas (Reis, 2015).

É importante ressaltar o papel da agricultura familiar no combate à pobreza. O crescimento do produto interno bruto (PIB) originado na agricultura reduz a pobreza duas vezes mais do que o crescimento do PIB equivalente em outros setores, de acordo com o Banco Mundial (Parente, 2003).

A agricultura familiar é um importante ator na proteção a biodiversidade e o meio ambiente, sendo uma fonte de diversidade genética que utiliza variedades de sementes e raças pecuárias bem adaptadas aos mais diversos ambientes. Também promove o uso de técnicas agroecológicas e tradicionais, apoiando o funcionamento saudável dos ecossistemas (Reis, 2015).

A legislação brasileira que define o conceito de agricultor familiar é amparada pela constituição brasileira e pela lei 11.326 / 2006. É considerado agricultor familiar aquele que desenvolve atividades econômicas no meio rural e atende a requisitos básicos, como não possuir propriedade rural maior que 4 módulos fiscais, sendo esta uma definição que muda de acordo com a região em que está localizada, uma vez que o módulo fiscal varia de 5 a 100 hectares conforme o município (Silva, 2006).

Ações que promovam a sustentabilidade da pequena atividade agrícola são fundamentais para manter a oferta e diversificação de produtos, gerar renda e minimizar seu impacto ambiental (Cabral, 2002).

De fato, na literatura, sustentabilidade em termos simples refere-se à condução de atividades para satisfazer as necessidades humanas hoje, sem comprometer a capacidade das gerações futuras de fazer o mesmo. É geralmente aceito que existem três pilares da sustentabilidade ambiental, econômico e social. O consenso aceita que a sustentabilidade ambiental é a mais crítica dos três (Santos, 2014). 
A agricultura familiar é central, principalmente na produção sustentável de alimentos, pois integra aspectos econômicos, sociais, culturais, ambientais e espirituais. Este potencial para múltiplas soluções permite que ela atenda ao duplo desafio, alimentar o mundo e curar o planeta (Parente, 2003).

Algumas das ações de sustentabilidade encontrados em locais de agricultura familiar são compostagem de resíduos orgânicos e adoção de outras técnicas de manejo e conservação do solo, construção de cisternas e proteção de nascentes e demais recursos hídricos, coleta de resíduos sólidos, cultivo de mudas e uso de sementes crioulas (Silva, 2006). A agricultura amazônica tem um contexto de mudança nas práticas agrícolas. A tecnologia inovadora evita a necessidade do cultivo tradicional de corte e queima da floresta. A diversidade agrícola do bioma da Amazônia é imensa. A agricultura é responsável pela produção de 65 culturas diferentes, que respondem por apenas 2,3\% da área do bioma, e são de produção sustentável (Santos, 2014).

Está documentado espécies amplamente cultivadas e consumidas na comunidade ribeirinha da Amazônia tais como, cacau (Theobroma cacao), cupuaçu (Theobroma grandiflorum), castanha-do-brasil (Bertholletia excelsa), piquiá (Caryocar sp.), açaí (Euterpe sp.), bacaba (Oenocarpus sp.) e tucumã (Atrocaryum aculleatum).

Mesmo quando os habitantes da antiga Amazônia começaram a plantar plantas domesticadas, eles também se engajaram em atividades de caça, pesca e coleta. A população não depende apenas do plantio agrícola. Ou seja, eles continuam a usufruir do que a floresta proporciona em diferentes momentos, e se relacionam com o espaço de maneiras distintas, interagem com a paisagem, o que transcende a questão da sobrevivência, mas também engloba a visão de mundo dessas populações (Cabral, 2002).

Atualmente, os ribeirinhos têm práticas de manejo semelhantes. Os quintais dos ribeirinhos da Amazônia são muito importantes para a subsistência das pessoas e para a compreensão dos recursos naturais dessas populações. A administração dos agricultores, o desenho e a função das espécies locais são os principais aspectos buscados por meio da pesquisa em biodiversidade agrícola (Santos, 2014).

A interação destes recursos com a população local é baseada nas suas necessidades, em geral caracterizam-se pela sua heterogeneidade e pela utilização de tecnologia simples, que mantém o equilíbrio ecológico natural. Desta forma, suas práticas agroecológicas podem determinar o possível diálogo entre a "tradição" e a nova forma de viver, de modo a enfrentar o quadro político do meio e utilizar os recursos e saberes da terra (Silva, 2006).

Os residentes ribeirinhos dependem principalmente do cultivo da mandioca, extração de plantas, pesca própria para alimentação e comercialização em pequena escala, quintais de frutas e vegetais e pequenos animais para seu sustento. $\mathrm{Na}$ comunidade, os principais produtos agrícolas por ordem de importância alimentar são mandioca, milho, feijão e arroz (Reis, 2015).

Essas culturas fazem parte da alimentação diária desses ribeirinhos. Neste sistema de ambiente agrícola, o cultivo de mandioca predomina, e $90 \%$ do espaço é cultivado. Entre as verduras, os destaques são pimentões, cebolinhas, couve, pimentadoce, pimenta-de-cheiro, coentro, abóbora, pimenta. A pimenta-doce apresentou frequência relativa de $90 \%$ e a pimenta-decheiro de $85 \%$, e a densidade de ambos é muito alta. Na categoria medicinal destacam-se o boldo, o crajiru e a mastruz, seguidos da carqueja, manjericão, gengibre e aloe vera (Parente, 2003).

O desenvolvimento da agricultura familiar desses povos é para subsistência, e está permeado por valores e características de sustentabilidade, pois permitem a gestão do uso dos recursos naturais, estando associados à capacidade reprodutiva física e cultural dos agricultores familiares, mantendo e garantindo que os recursos sejam usados na próxima geração (Reis, 2015).

\section{Resultados e Discussão}

Para realização do estudo de caso, foi estruturado um questionário de 5 perguntas. Os respondentes do estudo, são indivíduos que moram na região e praticam agricultura familiar, sendo 6 indivíduos (nominados neste estudo por A, B, C, D, E 
e F). Os nomes dos respondentes não serão divulgados por questões éticas. Todas as perguntas são focadas no conceito e compreensão de sustentabilidade e as práticas ribeirinhas para preservação (Tabela 1).

Tabela 1 - Perguntas do questionário.

\begin{tabular}{|l|l|}
\hline \multicolumn{2}{|c|}{ PERGUNTAS DO QUESTIONÁRIO } \\
\hline 1 & Você sabe o que é o desenvolvimento sustentável? \\
\hline 2 & Como você busca cuidar e preservar o meio-ambiente? \\
\hline 3 & $\begin{array}{l}\text { Você acha importante usufruir da natureza e de seus recursos de forma sustentável para que sempre } \\
\text { tenha recursos? Se sim, por quê? }\end{array}$ \\
\hline 4 & Você acredita que o desenvolvimento sustentável é algo fundamental para a preservação da floresta \\
& Amazônica para as próximas gerações Ribeirinhas? \\
\hline 5 & Por fim, em sua visão e opinião, todos os Ribeirinhos deveriam se preocupar em retirar da floresta \\
& Amazônica somente o necessário para a sobrevivência, gerando assim um desenvolvimento e \\
& cuidado sustentável? \\
\hline
\end{tabular}

Fonte: Autores (2021).

Conforme visto a teoria bourdiusiana defende que o comprometimento da sustentabilidade não está na perpetuação do desenvolvimento e sim na perpetuação vida. Mediante este conceito, os participantes apresentaram as seguintes respostas a Pergunta 1 na Tabela 2:

Tabela 2 - Respostas dos participantes a pergunta 1.

\begin{tabular}{|c|l|}
\hline Participante & \multicolumn{1}{c|}{ Resposta } \\
\hline A & É trabalhar com recursos do meio ambiente sem agredi-lo. \\
\hline B & É aquilo que agente planta e colhe para poder se sustentar. \\
\hline C & É retirar do meio ambiente de maneira sustentável. \\
\hline D & Sim. \\
\hline E & É trabalhar desenvolvendo sem agressão à natureza. \\
\hline F & É desenvolver trabalho que não agride a natureza. \\
\hline
\end{tabular}

Fonte: Autores (2021).

Evidencia-se que que o entendimento do desenvolvimento sustentável de uma forma abrangente aponta para uso de recursos naturais sem agredir o meio ambiente. Isso é também evidente na prática agrícola ribeirinho, onde seus usuários compreendem as importância da perpetuação dos recursos disponíveis, evidenciado pela resposta à Pergunta 2 (Tabela 3).

Tabela 3 - Respostas dos participantes a pergunta 2.

\begin{tabular}{|c|l|}
\hline Participante & \multicolumn{1}{|c|}{ Resposta } \\
\hline A & Não jogar lixos em vias públicas e rios, proteger para o desmatamento não crescer e etc. \\
\hline B & Limpando cuidando. \\
\hline C & Sempre cuidando de maneira adequada. \\
\hline D & Cuidando do solo fazendo a separação do lixo orgânico e não orgânico. \\
\hline E & Não jogar lixo em local inapropriado, não desmatar, não queimar. \\
\hline F & Não jogar lixo nos rios e não fazer grandes queimadas. \\
\hline
\end{tabular}

Fonte: Autores (2021). 
Mediante a Tabela 3, percebe-se que a prática comum da preservação do meio-ambiente se relaciona diretamente ao descarte de resíduos. Aponta-se que a poluição de solo e rios, pode afetar diretamente a agricultura de ribeirinho, entretanto notase uma preocupação entre eles não pelo ajuntamento de capital e riquezas e sim para conservação da vida. Isso também é mais evidenciado nas respostas dadas a pergunta 3 (Tabela 4).

Tabela 4 - Respostas dos participantes a pergunta 3.

\begin{tabular}{|l|l|}
\hline Participante & \multicolumn{1}{|c|}{ Resposta } \\
\hline A & Sim, pois nós somos seres racionais que dependemos dos mesmos todo o ecossistema. \\
\hline B & Sim, por que preservando usufruir mais o que ela nos oferece. \\
\hline C & Sim, porque sempre a natureza vai oferecer. \\
\hline D & Sim. \\
\hline E & Sim por que sem a natureza, não podem sobreviver por muito tempo. \\
\hline F & Sim! Para que nossos filhos e netos possam usufruir também. \\
\hline
\end{tabular}

Fonte: Autores (2021).

Observa-se que as respostas convergem dadas a pergunta 3 convergem para a necessidade e dependência do uso de recursos naturais e a importância de sua preservação, o que também harmoniza com a chama "necessidade cultivada" de Bourdieu, onde as práticas são feitas de forma totalmente consciente de sua sustentabilidade ou não.

A questão 4, foi voltadas a perpetuação de recursos para gerações futuras e as respostas (Tabela 5), apontaram para o que Bourdieu defende, um habitus sustentável que age de forma harmoniosa com o meio ambiente para preservação futura dos recursos.

Tabela 5 - Respostas dos participantes a pergunta 4.

\begin{tabular}{|c|l|}
\hline Participante & \multicolumn{1}{c|}{ Resposta } \\
\hline A & Sim, pois nem todos tem a ideia de sair para outras regiões. \\
\hline B & Sim, pois preservando as próximas geração usufruir. \\
\hline C & Sim. \\
\hline D & Sim. \\
\hline E & $\begin{array}{l}\text { Sim, pois se destruirmos a floresta, não só os ribeirinhos, mas toda a } \\
\text { população sofre com consequências. }\end{array}$ \\
\hline F & Sim. \\
\hline
\end{tabular}

Fonte: Autores (2021).

A última pergunta, foi voltada para a responsabilização de cada indivíduo quanto a preservação e perpetuação dos recursos em suas práticas. As respostas obtidas (Tabela 6) reafirma o chama estado coletivo de habitus de Bourdieu, tratando-se de ações e responsabilizações coletivas para uma sociedade ecológica. 
Tabela 6 - Respostas dos participantes a pergunta 5.

\begin{tabular}{|c|l|}
\hline Participante & \multicolumn{1}{c|}{ Resposta } \\
\hline A & $\begin{array}{l}\text { Sim, pois tudo o que eles precisam para a sua sobrevivência está em sua volta, se os mesmo não } \\
\text { preservarem, acaba não somente para eles mas para seus netos, bisnetos etc. }\end{array}$ \\
\hline B & Sim. \\
\hline C & Sim. \\
\hline D & Sim. \\
\hline E & $\begin{array}{l}\text { Todo mundo e não só os ribeirinhos, pois sem a floresta nós não sobrevivemos, dependemos dela } \\
\text { para tudo. }\end{array}$ \\
\hline F & Sim. \\
\hline
\end{tabular}

Fonte: Autores (2021).

A partir da visão de Bourdieu, para uma sociedade ecológica fundada a partir de ações individuais inseridas no meio ambiente e não o contrário, o habitus do indivíduo irá ditar o futuro sustentável ou destruído do mundo. Isso se torna possível onde o ajuntamento da riqueza não é o principal fator quando se utiliza recursos naturais, seu uso somente algo necessário, percebe-se que a atividade agrícola familiar dos ribeirinhos amazônicos se inserem nesse contexto.

Suas ações convergem na dependência e necessidade dos recursos oferecidos pelo meio que vivem, e compreendem a importância da preservação da vida, indo além do desenvolvimento e praticando ações sustentáveis.

\section{Conclusão}

Conclui-se que os ribeirinhos da região amazônica, embora seja considerados por muitos desinformados, apresentam grande responsabilidade e entendimentos de preservação quanto ao meio ambiente.

Por meio do estudo de caso, conclui-se que embora a teoria bourdiusiana não seja conhecida por leigos, a partir das entrevistas realizadas nota-se sua presença nas ações dos respondentes de uma forma inconsciente. Como visto, a teoria bourdiusiana trabalha com as sensibilidades e disposições incorporadas por interação familiar, educacional e social, sendo estes evidenciadas nas respostas obtidas, o que também é notado a partir das práticas agrícolas familiares encontradas na literatura, mostrando uma responsabilidade individual em perpetuação da vida.

O fato de a agricultora familiar nessa região ser frequentemente familiar, aponta diretamente para a subsistência dos praticantes, mais uma vez confirmando a teoria bourdiusiana que onde há o ganho de capital econômico sem anular em algum momento a sustentabilidade.

\section{Referências}

Bartholomeu, D. B., \& Caixeta-Filho, J. V. (2011). Logística ambiental de resíduos sólidos. Atlas.

Borim-Souza, R., Woitas, N. M. A., Zanoni, B. L. \& Chiba, J. H. F. Internationalisation and sustainability as a field: a contingent view of comparative management via Bourdieusian sociology. Int. J. Comparative Management, 1(1), 26-44, .2018.

Brasil. Lei $\mathrm{n}^{\mathrm{o}}$ 11.326, de 24 de julho de 2006. Estabelece as diretrizes para a formulação da Política Nacional da Agricultura Familiar e Empreendimentos Familiares Rurais. < www.planalto.gov.br/ccivil_03/_ato2004-2006/2006/lei/111326.htm>.

Cabral, J. Olhares sobre a realidade do ribeirinho: uma contribuição ao tema. Presença - Revista de Educação, Cultura e Meio Ambiente, 209(24),

Carvalho, I. C. de M., \& Steil, C. A. O habitus ecológico e a educação da percepção: fundamentos antropológicos para a educação ambiental. Educação e Realidade. 34.

Collis, J., \& Hussey, R. (2005). Pesquisa em administração. (2a ed.), Bookman, p.349

Gil, A. C. (2014). Como elaborar projetos de pesquisa. (4a ed.), Atlas 
Research, Society and Development, v. 10, n. 15, e438101523270, 2021

(CC BY 4.0) | ISSN 2525-3409 | DOI: http://dx.doi.org/10.33448/rsd-v10i15.23270

Hurtado, P. S. Assessing the use of Bourdieu's key concepts in the strategy-aspractice field. Competitiveness Review: An International Business Journal, 20(1), $52-61$

Lakatos, E. M., Marconi, M. A. (2011) Fundamentos de metodologia científica. (5a ed.), Atlas

Leite, P. R. Logística reversa: meio ambiente e competitividade. Prentice Hall

Lessa, B. S. Disposições Sustentáveis - Um olhar biográfico e sociológico para Educação para a Sustentabilidade. Tese (Doutorado) -- Universidade Federal do Rio Grande do Sul, Escola de Administração, Programa de Pós-Graduação em Administração, Porto Alegre, BR-RS, 2019.

Loyal, S. Bourdieu's Theory of the State. Londres: Palgrave, 2017. habitus na sociologia de Pierre Bourdieu. Dissertação de Mestrado em Sociologia da Universidade de Brasília, 2007.

Michael, M. H. Metodologia e Pesquisa Científica Em Ciências Sociais. Capa ilustrativa. 2015, Editora: atlas.

Montibeller, F. G. (2007). Empresas, desenvolvimento e ambiente: diagnóstico e diretrizes de sustentabilidade. -. - (coleção ambiental). Manole

Parente, V. M. A. Economia da Pequena Produção na Várzea: sobrevivência das famílias ribeirinhas. In: Ribeiro, M. O. A. \& Fabré, N. N. (org.). SAS - Sistemas Abertos Sustentáveis: Uma alternativa de gestão ambiental na Amazônia. EDUA - Editora da Universidade Federal do Amazonas. Manaus-Amazonas, 2003.

Paula, M. B., Souza, M. T. S., \& Souza-Pinto, H. O papel das cooperativas de reciclagem nos canais reversos pós-consumo. RAE, 52(2). 246-262.

Pereira, A. L. (2012). Logística reversa e sustentabilidade. Cengage Learning.

Reis, A. A. Desenvolvimento sustentável e uso dos recursos natutrais em areas de várzea do território do Baixo Tocantins da Amazônia Paraense: limites, desafios e possibilidades. Tese (Doutorado) - Universidade Federal do Pará, Núcleo de Altos Estudos Amazônicos, Programa de Pós-Graduação em Desenvolvimento Sustentável do Trópico Úmido. Belém, 2015.

Santos, V. B Acordos de Pesca e "capital social ribeirinho" na Amazônia Oriental: a dimensão cultural em concepções contemporâneas de desenvolvimento e sustentabilidade. In: ENCONTRO ANUAL DA ANPOCS, 38., 2014. Caxambu - MG. Anais... Caxambu - MG: ANPOCS, 2014.

Shibao, F., Moori, R., \& Santos, M. R. (2010). A Logística Reversa e a Sustentabilidade Empresarial. In: SEMEAD. FEA/USP

Silva, S. S. C. Estrutura e dinâmica das relações familiares de uma comunidade ribeirinha da região amazônica. Tese de Doutorado, Universidade de Brasília, 2006

Tadeu, H. F. B. (2012) Logística Reversa e Sustentabilidade. Cengage Learning.

Vegara, S. C. (2010). Projetos e Relatórios de Pesquisa em Administração. (12a ed.), Atlas. 